Article

\title{
Particle-Crushing Characteristics and Acoustic- Emission Patterns of Crushing Gangue Backfilling Material under Cyclic Loading
}

\author{
Junmeng $\mathrm{Li}^{1,2}{ }^{10}$, Yanli Huang ${ }^{1, *}$, Zhongwei Chen ${ }^{2}$, Meng $\mathrm{Li}^{1}{ }^{1}$, Ming Qiao ${ }^{1}$ and Mehmet Kizil ${ }^{2}$ \\ 1 State Key Laboratory of Coal Resources and Safe Mining, School of Mines, China University of Mining \& \\ Technology, Xuzhou 221116, China; lijunmeng1201@163.com (J.L.); lvlippa@163.com (M.L.); \\ tb16020013b1@cumt.edu.cn (M.Q.) \\ 2 School of Mechanical and Mining Engineering, The University of Queensland, Queensland 4072, Australia; \\ zhongwei.chen@uq.edu.au (Z.C.); m.kizil@uq.edu.au (M.K.) \\ * Correspondence: huangyanli6567@163.com
}

Received: 13 May 2018; Accepted: 3 June 2018; Published: 7 June 2018

\begin{abstract}
In solid backfilling coal mining (SBCM), the crushed gangue backfilling material (CGBM) is generally compacted circularly by a compaction machine in order to reduce its compressibility. In this cyclic compaction process, the particles are crushed, which has a significant effect on the deformation resistance of CGBM. However, the deformation resistance of CGBM is critical for controlling overburden strata movement and ground surface subsidence. This study implemented an experimental approach to investigate the particle-crushing characteristics and acoustic-emission (AE) characteristics of CGBM during constant-amplitude cyclic loading (CACL). At the same time, the relationship between particle crushing and AE signals was established. The results showed that the gangue particles were generally in the shape of irregular convex polyhedrons with more edges and angles that were prone to breakage. It also demonstrated that both the crushing ratio $\left(B_{\mathrm{g}}\right)$ and the newly produced fine granule content increased with the cyclic loading times. The content of newly generated fine particles can reflect the particle-crushing conditions to a certain extent. What is more, it was found that the CGBM samples exhibited an apparent Felicity effect during $\mathrm{CACL}$, and AE signals were the most active during the first loading cycle. The crushing ratio of CGBM was highly correlated to the AE signals, which indicated that AE signals can be used to reflect the particle-crushing situation of CGBM. This study is of great significance for obtaining an in-depth understanding of the mechanical properties of CGBM, as well as providing guidance for the engineering practice of SBCM.
\end{abstract}

Keywords: crushing gangue backfilling material; cyclic loading; particle crushing; acoustic emission; solid backfilling coal mining

\section{Introduction}

Solid backfilling coal mining (SBCM) is a green mining technology proposed for use in difficult coal mining situations, such as mining under buildings, railways, and water bodies, and for solving the problem of the opening dumping of gangue on the ground. This technology is aimed at backfilling solid waste, which mainly includes crushed coal gangue and fly ash, into the underground goaf, thus bearing the majority of the overburden load and recovering coal resources under buildings, railways, and water bodies. It can effectively control overburden movement, thus increasing the coal recovery ratio. At the same time, the gangue heap on the ground surface can be well disposed with the use of the technology, which can significantly reduce environmental pollution [1-4]. In the SBCM process, 
the vertical feeding system transports solid backfill material from the waste storeroom under the mine to the scraper conveyor at the rear of the hydraulic support. Then, the solid backfill material fills the goaf by being unloaded from the discharge port in the scraper conveyor. After that, the compaction mechanism, as a key structure, is applied to push and compact the solid backfill material, which is repeated for several cycles to connect the immediate roof with the required density. Finally, the solid backfill material will serve as the main supporting body to bear the load of the overlaying strata [5-8]. Crushed gangue backfilling material (CGBM) is most commonly used as a kind of solid backfill material for SBCM. When it is filled into the goaf, the phenomenon of particle crushing occurs in the process of cyclic compaction by the compaction mechanism. As a result, its internal structure is changed, which has a significant impact on its deformation resistance. Meanwhile, obvious acoustic emission (AE) signals containing abundant omen information of progressive failure can be picked up in the process of particle crushing [9-12]. At present, AE technology has been widely used in geotechnical engineering to study the fracture characteristics of coal and rock. Many studies have shown that the deformation resistance of solid backfill material is a key factor that determines the backfill quality [13-15]. Therefore, in order to reveal the deformation resistance mechanism of CGBM, it is crucial to study the particle-crushing characteristics of CGBM during cyclic loading.

Yilmaz et al. explains that the use of paste for surface and underground disposal of acid-generating tailings as an alternative to traditional methods is opening the way for a new era in mineral waste-management practices. At the same time, they examined the influence of a desliming pretreatment of mine tailings on the strength development of the resultant paste backfill [16-18]. The CGBM in essence is a kind of nonsticky granular material. A large amount of research has been conducted by scholars on the effect of the particle crushing of nonsticky granular material on its engineering properties. Marsal et al. conducted an experimental study on the particle crushing of rockfill material, and the results showed that particle crushing is related to the shape, strength, size, density, gradation, and strain of the particle [19-23]. Kjaernsli et al. conducted a triaxial compression test of a sand sample and found that irregular particles with rough surfaces are more prone to crush at the given stress [24]. Hall et al. found that under certain stress, the crushing of well-graded sand happens much less frequently than that of poorly graded sand [25]. Through a large-scale triaxial test, Liu et al. demonstrated that particle crushing increased along with the confining pressure [26]. Li et al. studied the effect of rock properties, particle gradation, rockfill density, confining pressure, and stress status of coarse-grained soil on its particle-crushing characteristics [27-30]. Current research mainly focuses on the effect of different particle gradation, confining pressure, and stress situations on the particle-crushing characteristics of granular material. However, very few studies have focused on the particle-crushing characteristics of CGBM under cyclic loading conditions. Li [31], Liu [32], and Zhou [33] have analyzed the effects of particle size and particle crushing of crushed gangue backfill materials on surface subsidence and energy evolution.

In order to study the particle-crushing characteristics of CGBM under cyclic loading conditions, systematic experimental research was carried out in this study. During the experiment, an AE monitoring system was introduced to monitor the AE signals of the samples. Further, by analyzing the experimental data, the relationship between AE signals and particle crushing was established and the particle-crushing mechanism of CGBM was revealed. The research results are extremely important to get an in-depth understanding of the mechanical properties of CGBM and to reveal the impact of the particle-crushing mechanism on the deformation characteristics of CGBM.

\section{Materials and Methods}

\subsection{The Materials Used}

According to the mineralogical characteristics of the gangue, the material can be categorized into four different types: clay mineral, sandstone, carbonate rock, and alumina mineral [34]. The CGBM used in SBCM mainly comes from two sources. The first source is the rock material produced during 
the excavation process of rock roadways and coal roadways; the gangue from this source is called "excavation gangue", which mainly consists of sandstone. The other source is the rock material discharged from the coal washing process; the gangue from this source is called "washing gangue". The CGBM used in the following experiments was taken from the "excavation gangue" of the No. 12 gangue dump of Henan Province in China and its lithology is sandstone.

\subsection{Sample Preparation}

Before the experiments, the gangue was first crushed by a crusher and then filtered by a classifying screen to obtain five different distributions of particle sizes, which were 10-20 mm, 20-30 mm, 30-40 mm, 40-50 mm, and 50-60 mm. Gangue of various particle sizes was screened as shown in Figure 1. When preparing the samples, the weight of the gangue in each particle-size group was $3.2 \mathrm{~kg}$, and the mass ratio was 1:1:1:1:1.
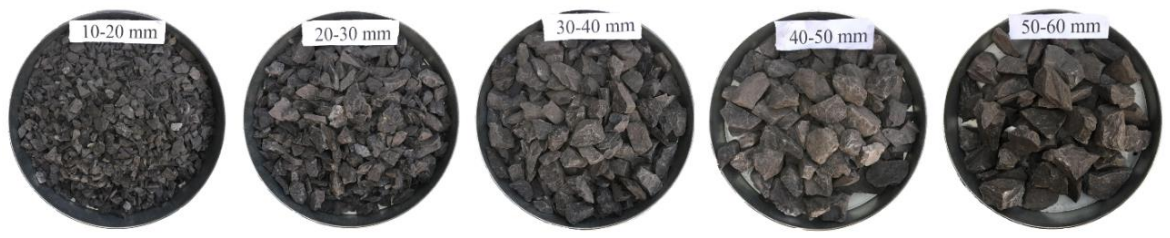

Figure 1. The preparation of samples.

\subsection{Image Processing Analysis}

The CGBM used in SBCM are those treated by crushing and sieving, the particle size of which is usually 0-70 $\mathrm{mm}$. In this paper, ImageJ image processing software was used to carry out statistical analysis of the shape of gangue with different sizes. The detailed analysis procedures are as follows: (1) a digital camera was used to capture high-definition digital images of randomly selected gangue blocks (shown in Figure 2a); (2) binary processing was performed on the input digital image by the ImageJ image processing software (shown in Figure 2b); (3) the boundary contour of the gangue block was extracted by using the particle analysis function of ImageJ image processing software (shown in Figure 2c).

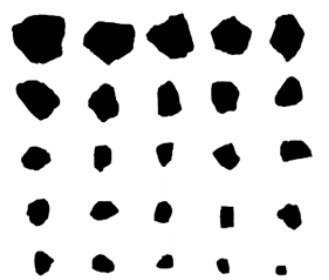

(a)

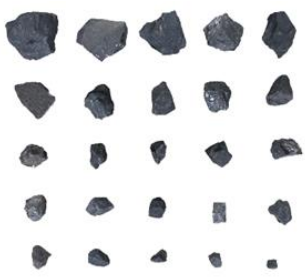

(b)

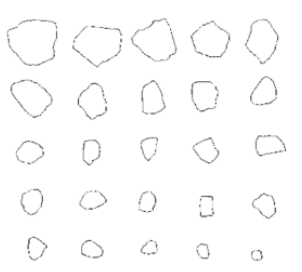

(c)

Figure 2. Statistical analysis of the shape of the gangue block. (a) High-definition digital image; (b) binary processing image; (c) the boundary contour image.

According to statistical analysis, the gangue particles were generally in the shape of irregular convex polyhedrons with more edges and angles that are prone to breakage. The lengths of the long and short axes of the gangue blocks was approximate.

\subsection{Test Equipment}

\subsubsection{Scanning Electron Microscope (SEM)}

SEM is a new type of electronic optical instrument. It has the characteristics of simple sample preparation and high-image resolution. Over the decades, SEM has been used in many fields, such as 
biology, medicine, and engineering. In recent years, this technique has been used to observe the surface characteristics of rock, metals, and other materials. In this study, SEM, was used to analyze the density of the CGBM under various magnifications, and Figure 3 shows the FEI Quanta TM 250 SEM (FEI, Hillsborough, OR, USA).

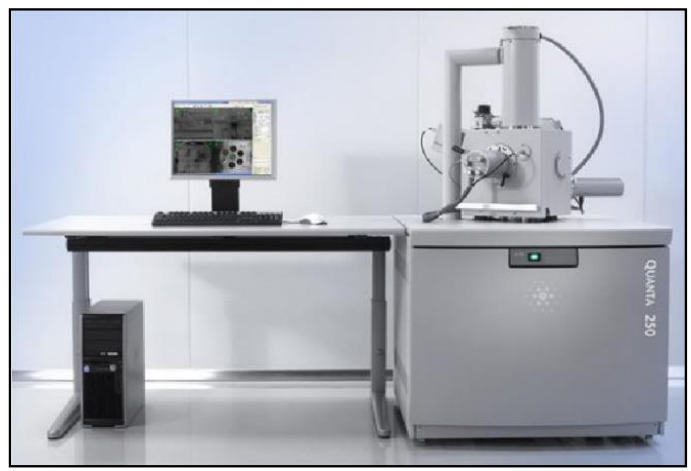

Figure 3. FEI Quanta TM 250 SEM.

\subsubsection{Loading Control System}

The loading control system applied in the following experiments was the MTS815 rock mechanics electrohydraulic servo test system (MTS Company, Eden Prairie, MN, USA). In the experiments, the stress control mode for loading was employed and the loading rate was set at $1 \mathrm{kN} / \mathrm{s}$. The container for the CGBM was a special steel chamber used to test the mechanical properties of the solid backfill material in SBCM. The steel chamber was processed from a Q235 seamless steel tube, with an inner diameter of $350 \mathrm{~mm}$, a cylindrical depth of $378 \mathrm{~mm}$, a loading platen thickness of $40 \mathrm{~mm}$, and a maximum loading height of $338 \mathrm{~mm}$. In the following experiments, the filling height was $338 \mathrm{~mm}$. The loading process was carried out by a loading platen and a dowel bar. The load control system and the steel chamber are shown in Figure 4.

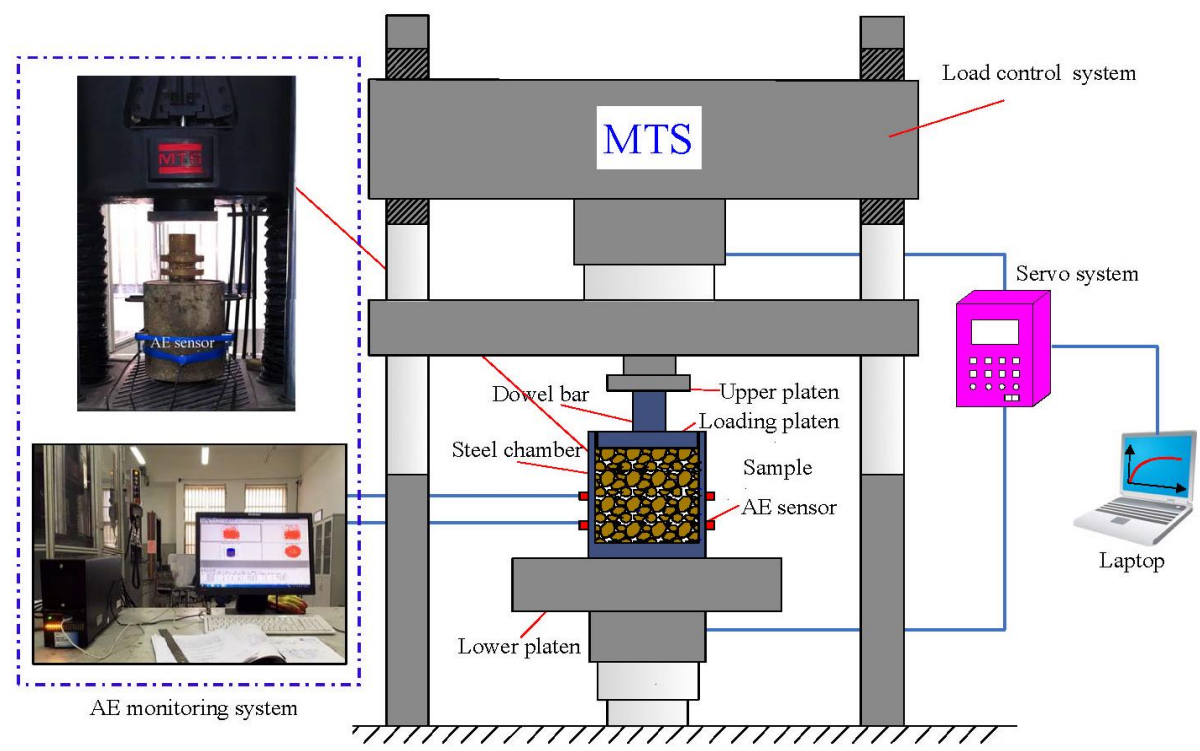

Figure 4. Loading control system and steel chamber.

\subsubsection{AE Monitoring Systems}

An AE monitoring system (PCI-2 model produced by Physical Acoustic Corporation, Princeton, NJ, USA) was employed in the experiments. The PCI-2 system can automatically count AE events and 
store AE signals, as well as communicate with computers and manage to monitor and locate AE events in real time. The AE monitoring system is shown in Figure 4. Six Nano30 AE sensors, the working frequency of which was $100-400 \mathrm{kHz}$, were used in the experiments. The AE sensors were equally arranged in two layers and placed on the external surface of the steel chamber, as is shown in Figure 5. To ensure the coupling effect, Albany grease was lubricated on the contact area between the sensors and the external surface of the steel chamber. Air was squeezed out and tape was employed to ensure that the sensors were firmly stuck on the external surface of steel chamber. AE signals are sensitive to surrounding noises. After continuous adjustment of the threshold, we found that when the fixed threshold was set at $45 \mathrm{~dB}$, the noises could be largely blocked out. Finally, the fixed threshold was set at $45 \mathrm{~dB}$ in the following experiments. When running the experiments, it was important to assure that the loading control system and AE monitoring system drove synchronously, during which the AE monitoring system automatically collected and recorded AE signals.
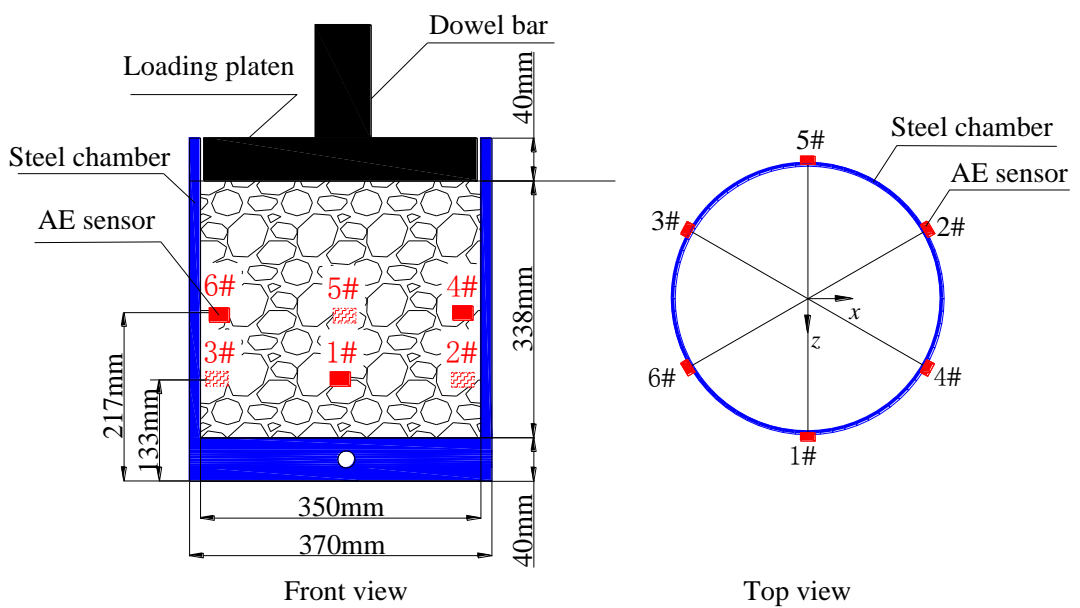

Top view

Figure 5. Layout diagram of sensors.

\subsection{Experiment Design}

In order to obtain the basic physical properties of CGBM, SEM was first used to analyze the microstructure of CGBM under various magnifications. Then, the Image image processing software was applied to carry out statistical analysis of the shape of the gangue with different diameters.

In order to study the influence pattern of cyclic loading times on the particle-crushing and AE characteristics of the CGBM, a constant-amplitude cyclic loading (CACL) test with different loading times was designed. For each loading cycle, the upper stress limit was set to $2 \mathrm{MPa}$, and the lower stress limit was set to $0 \mathrm{MPa}$. During the experiments, the loading control system and AE monitoring system ran simultaneously. After CACL test, every sample was screened to obtain the particle with the required size. The detailed test plans are presented in Table 1.

Table 1. Experiment design.

\begin{tabular}{cc}
\hline Experiment Number & Experiment Description \\
\hline $1 \#$ & Cyclic loading 1 time \\
$2 \#$ & Cyclic loading 2 times \\
$3 \#$ & Cyclic loading 3 times \\
$4 \#$ & Cyclic loading 4 times \\
$5 \#$ & Cyclic loading 5 times \\
$6 \#$ & Cyclic loading 6 times \\
$7 \#$ & Cyclic loading 7 times \\
\hline
\end{tabular}




\section{Results and Discussion}

\subsection{The Microstructure of CGBM}

Figure 6 shows SEM images of CGBM under different magnification.
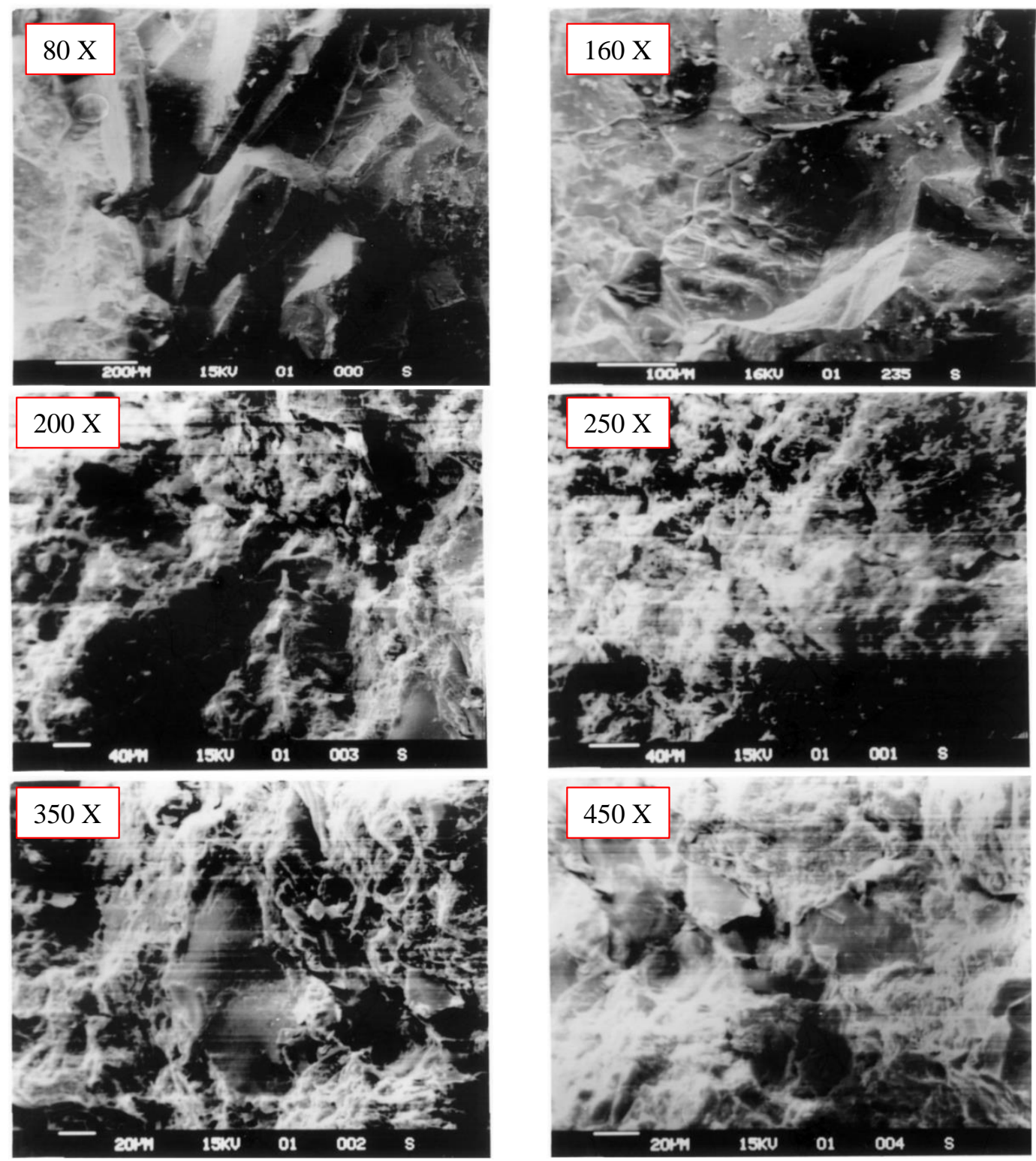

Figure 6. SEM images of CGBM under various magnification.

According to Figure 6, it can be seen that the coarse particles form a certain skeletal framework which is filled with smaller particles. The surface is rough and irregular with a coarse texture. This makes CGBM have greater bite force and friction force, which are conducive to improving the bearing capacity of CGBM. Many pores are visible. However, there are not many large holes or fissures. 


\subsection{Particle-Crushing Characteristics}

\subsubsection{Quantitative Indexes of Particle Crushing}

In the process of loading, the gangue particles are crushed. In order to research the influence of particle crushing on the strength and deformation characteristics of crushed gangue, there is a need to quantitatively reflect the crushing degree of the particles. Currently, the Marsal crushing ratio $\left(B_{\mathrm{g}}\right)[19]$, particle size control difference $(B)$ [35], as well as relative crushing ratio $\left(B_{\mathrm{r}}\right)$ [23] are considered as three different kinds of quantitative indexes that are the most commonly used in geotechnical engineering. The Marsal crushing ratio $\left(B_{\mathrm{g}}\right)$ is defined as the sum of the positive values of difference in particle contents having different gradation before and after the test, which is expressed as a percentage. Its computational formula is as follows:

$$
B_{\mathrm{g}}=\sum W_{\mathrm{ki}}-W_{\mathrm{kf}}
$$

where $W_{\mathrm{ki}}$ is the particle content of a certain gradation in size before the test, and $W_{\mathrm{kf}}$ is the corresponding particle content of the identical gradation in size after the test.

The Marsal crushing ratio is a multigradation difference-value summation method, which can reflect the full aspect of the crushing condition of the particles. Having the merits of simple calculation and clear physical definition as well as high accuracy that can meet the need of practical engineering, the Marsal crushing ratio $\left(B_{\mathrm{g}}\right)$ was used in this study as an essential quantitative index to describe the crushing condition of the particles.

\subsubsection{Analysis of Test Results}

After the CACL test, the samples were rescreened. The particle-size distribution and the particle-crushing ratio $\left(B_{\mathrm{g}}\right)$ of CGBM samples were obtained, as is shown in Table 2.

Figures 7 and 8 show the relationship between the particle-crushing ratio and cyclic loading times and the relationship between newly generated fine particle content and cyclic loading times, respectively.

Table 2. The particle-size distribution and the particle-crushing ratio $\left(B_{\mathrm{g}}\right)$.

\begin{tabular}{|c|c|c|c|c|c|c|c|}
\hline \multirow[b]{2}{*}{$\begin{array}{l}\text { Experiment } \\
\text { Number }\end{array}$} & \multicolumn{7}{|c|}{ The Particle-Size Distribution/\% } \\
\hline & $\begin{array}{c}0-10 \mathrm{~mm} \\
\text { (Newly Generated } \\
\text { Fine Particle) }\end{array}$ & $10-20 \mathrm{~mm}$ & $20-30 \mathrm{~mm}$ & $30-40 \mathrm{~mm}$ & $40-50 \mathrm{~mm}$ & $50-60 \mathrm{~mm}$ & $B_{\mathrm{g}}$ \\
\hline Before the test & 0 & 20 & 20 & 20 & 20 & 20 & 0 \\
\hline 1\# & 9.94 & 22.75 & 20.94 & 17.63 & 14.47 & 14.27 & 13.63 \\
\hline $2 \#$ & 10.81 & 25.22 & 19.59 & 19.72 & 11.66 & 13 & 16.03 \\
\hline 3\# & 11.94 & 25.84 & 19.34 & 18.69 & 14.03 & 10.16 & 17.78 \\
\hline $4 \#$ & 14.22 & 24.75 & 19.34 & 15.66 & 18.81 & 7.22 & 18.97 \\
\hline 5\# & 16.51 & 22.41 & 20.49 & 18.34 & 10.31 & 11.94 & 19.41 \\
\hline 6\# & 17.49 & 22.1 & 20.13 & 12.6 & 12.59 & 15.09 & 19.72 \\
\hline $7 \#$ & 17.96 & 21.94 & 20.08 & 17.69 & 12.39 & 9.94 & 19.98 \\
\hline
\end{tabular}




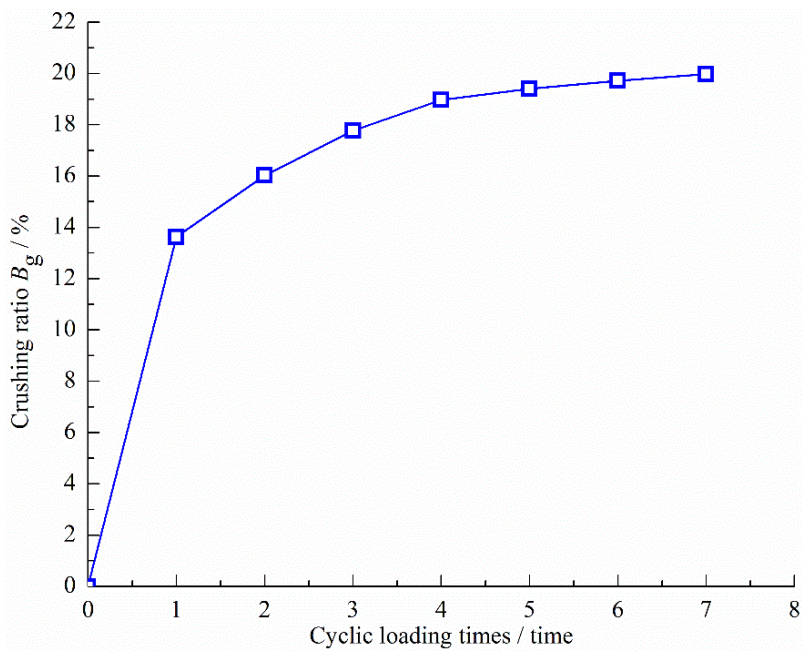

Figure 7. The relationship between the particle-crushing ratio $B_{\mathrm{g}}$ and cyclic loading times.

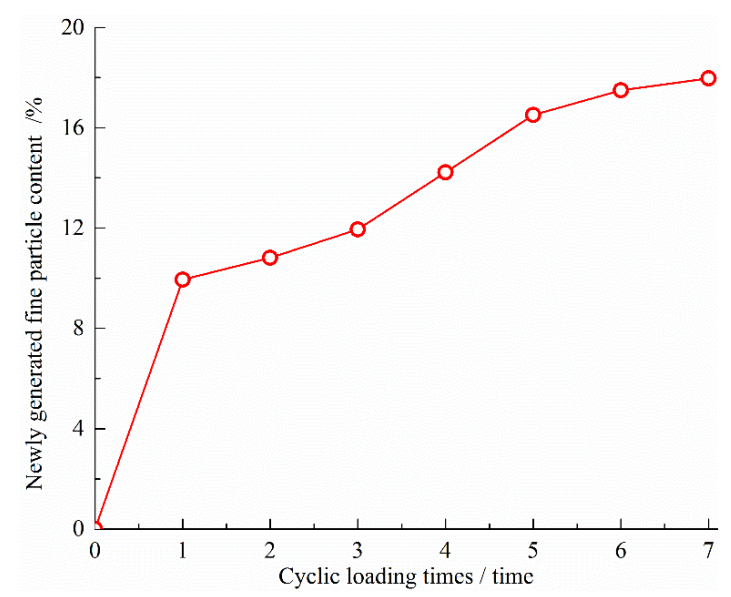

Figure 8. The relationship between newly generated fine particle content and cyclic loading times.

According to the test results, the impact pattern of cyclic loading times on the particle-crushing characteristics of CGBM can be described as follows:

(1) In the CACL experiments, the crushing ratio $\left(B_{\mathrm{g}}\right)$ and newly produced fine particle $(0-10 \mathrm{~mm})$ content all increased with the cyclic loading times. However, when cyclic loading times exceeded 4 , the crushing ratio gradually tended to be stable. This is because the phenomenon of particle crushing occurs in each cyclic loading process. When the cyclic loading times were more than 4, the CGBM formed a stable structure. The particles in CGBM had been fully adjusted and the small particles filled the gap between the large particles, so the stress concentration in the sample was reduced, which led to a reduction of the particle-crushing phenomenon.

(2) The change rules of newly generated fine particle content and the crushing ratio under cyclic loading conditions were similar. This is due to the fact that the crushing forms of the gangue blocks of CGBM samples are mainly edge and corner fractures, leading gangue blocks of CGBM to be mostly crushed into small particles $(0-10 \mathrm{~mm})$.

(3) In the CACL experiments, the process of particle crushing had a significant impact on the particle content of CGBM samples with the size of $40-60 \mathrm{~mm}$, causing its content to decrease from $40 \%$ to $25 \%$ compared to its counterpart with the size of $0-10 \mathrm{~mm}$, which increased dramatically. In terms of the three other particle gradations, there was a slight decrease in the particle content with the 
size of 30-40 $\mathrm{mm}$ and a marginal rise in its counterpart with the size of 10-20 $\mathrm{mm}$, while particle content of 20-30 mm did not change substantially.

\subsection{AE Pattern}

The internal defects of rocks and other solid material can be activated by external forces, thereby causing damage, during which time strain energy is released in the form of elastic waves, which quickly spreads in the solid material, generating the AE phenomenon [36]. In the cyclic loading process, when the load is smaller than the previous maximum bearing capacity, the AE will increase significantly, which is known as the Felicity effect [37]. In the experiment, the internal particle-crushing situation during the loading process was reflected by the AE signals.

In the CACL process of CGBM, the evolution characteristics of AE counts and cumulative AE counts are shown in Figures 9 and 10, respectively. The relationship between cumulative AE counts and the crushing ratio of CGBM under the conditions of different cyclic loading times is shown in Figure 11.

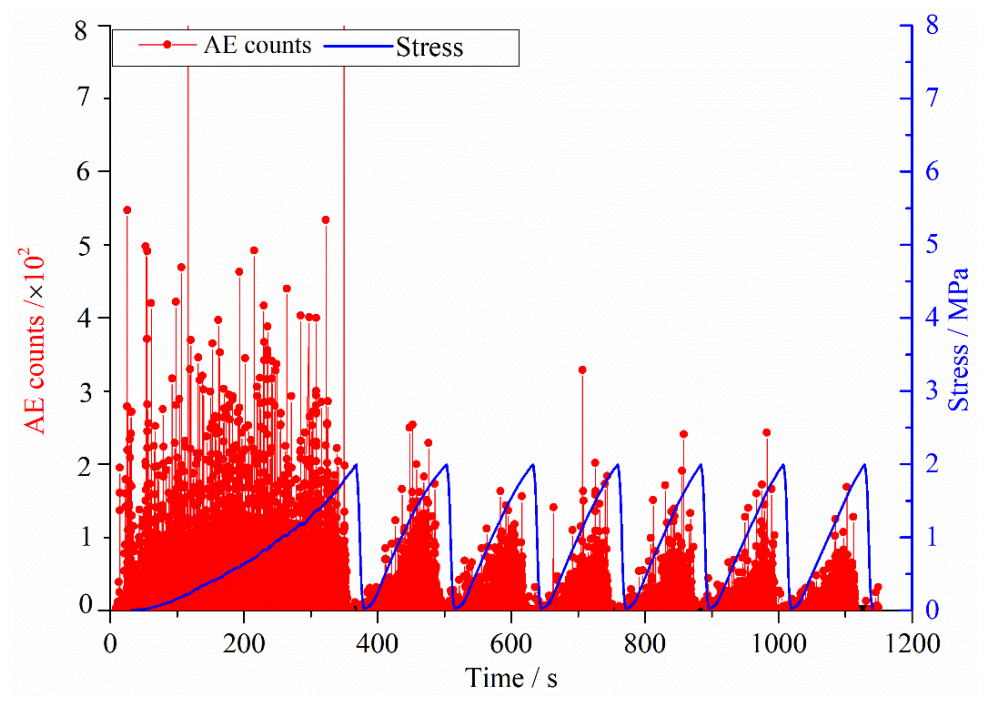

Figure 9. The evolution characteristics of AE counts under the CACL experiment.

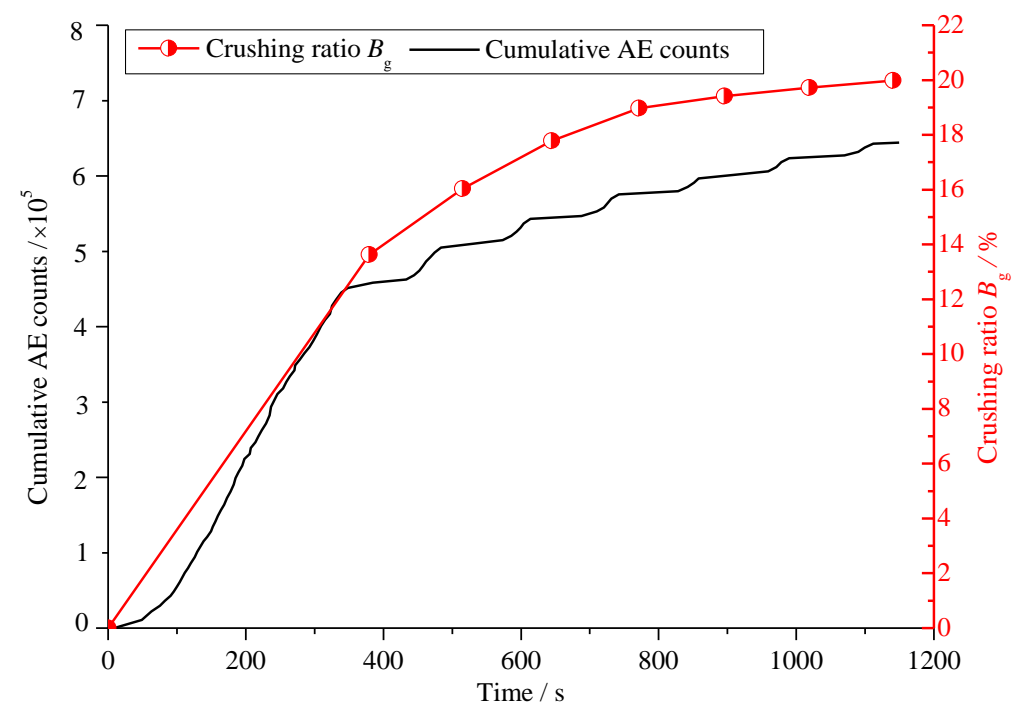

Figure 10. The evolution characteristics of cumulative AE counts under the CACL experiment. 


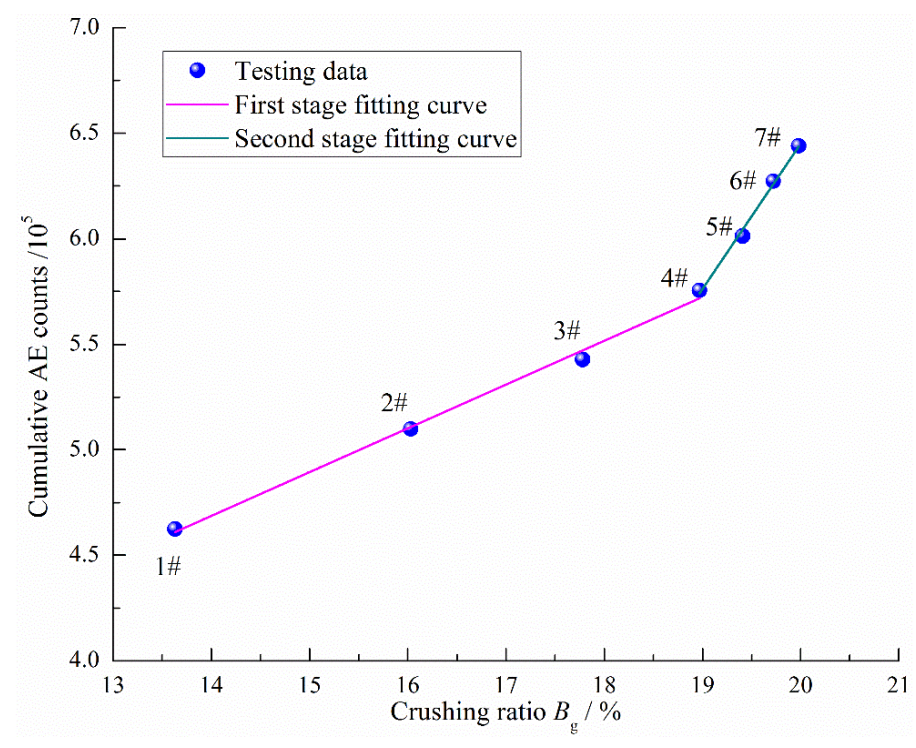

Figure 11. The relationship between cumulative AE counts and crushing ratio.

From Figure 9 to Figure 11, the following results were obtained:

(1) An apparent Felicity effect on CGBM samples occurred during the CACL process, i.e., AE signals were generated at the initial stage of each loading cycle, which demonstrates that the particle-crushing phenomenon happened every loading cycle. This is because CGBM is a kind of anisotropic bulk material. The particles are in constant adjustment and change during loading. The stress state within CGBM will also change constantly, and this state is irreversible.

(2) In each loading cycle, the AE signals first witnessed a gradual increase and then a dramatic decrease. The AE activity was mainly observed in the loading phase, and in particular, it was most active in the first loading cycle. The cumulative AE counts of the first loading cycle accounted for $71.1 \%$ of the total counts of the whole process. This is because the original samples were relatively loose and had a number of angle-angle and angle-surface contacts between internal particles. When the samples bear the load, stress concentration is likely to occur when the load is transferred between particles, causing many particles to be crushed. As a result, a large number of acoustic emission signals are emitted.

(3) As the cyclic loading times increased, the total AE counts in a single loading cycle gradually decreased, which was confirmed by cumulative AE counts' cyclic loading time curve, in which there was a graded upward trend and the gradient gradually decreased. This is because the smaller particles generated by particle crushing during the loading process fill the pores of the samples, leading to an increase in the coordination number between particles and a drop in the possibility of stress concentration. The internal structure of the samples is gradually adjusted and optimized with the increase of cyclic loading times, meaning that the particle-crushing phenomenon can be significantly improved when the samples bear the same load again.

(4) During the cyclic loading process, the crushing ratio of crushed gangue was highly correlated to the time-varying characteristics of AE signals. The cumulative AE counts increased with the crushing ratio, and there existed a piecewise linear relationship between these two factors. The linear changing trend can be divided into two stages. In the first stage, when the crushing ratio $B_{\mathrm{g}}$ amounted to 19 or less (cyclic loading times from 1 to 4 ), the cumulative AE counts increased with the crushing ratio of the samples, but the rate of increase was relatively slow. However, in the second stage, when the crushing ratio $B_{\mathrm{g}}$ was between 19 and 19.98 (cyclic loading times from 4 to 7 ), the cumulative $\mathrm{AE}$ counts still showed a linear increasing trend as the crushing ratio of the samples increased, but the rate of increase was significantly higher than 
that in the first stage. It can be observed that, under the compression conditions, $\mathrm{AE}$ signals were closely related to the crushing ratio of CGBM, meaning that the AE signals can closely reflect the internal particle-crushing situation of the CGBM samples.

\subsection{A Comparative Discussion with Existing Studies}

In the field of SBCM, the current research on the mechanical properties of CGBM mainly focuses on the continuous loading condition, but there is no research on its mechanical properties under the cyclic loading condition. However, in field engineering practice, CGBM is usually subjected to the cyclic loading of the compaction mechanism in goaf. Therefore, the above research results can more truly reflect the mechanical properties of CGBM under the stress state in goaf. Besides, at present, the final crushing ratio of CGBM samples is mainly obtained by screening the samples after the experiment, but there is no research on particle-crushing characteristics during the loading process. In this paper, a new method of monitoring the samples' AE signals during compression by an $\mathrm{AE}$ system was proposed to study the particle-crushing state. Further, the relationship between AE signals and particle crushing was established. This provides a feasible way to study the particle-crushing characteristics during loading.

\section{Conclusions}

In order to study the particle-crushing characteristics and AE patterns of CGBM under cyclic loading conditions, a systematic experiment has been carried out in this study. The relationship between AE signals and particle crushing was established and the particle-crushing mechanism of CGBM was revealed. The research results were extremely important to get an in-depth understanding of the mechanical properties of CGBM. From this study, the following conclusions have been obtained:

(1) As for CGBM, the coarse particles that are filled with smaller ones form a certain skeletal framework. The gangue particles are generally in the shape of irregular convex polyhedrons with more edges and angles, which are prone to breakage.

(2) During the CACL process, the crushing ratio of CGBM increased with the cyclic loading times. When the cyclic loading times exceeded 4, the crushing ratio of samples gradually became stable. The particle crushing had a more significant impact on the samples with larger gradations in size than their counterparts with a relatively smaller gradation. The content of newly produced fine particles had a strong correlation with the crushing ratio, which can reflect the particle-crushing conditions.

(3) The CGBM samples exhibited an apparent Felicity effect during the CACL process, and AE signal activities were the most active during the first loading cycle. The internal structure of the samples was gradually adjusted and optimized with the increase of cyclic loading times, which means that the samples tend to be in a more stable state.

(4) The crushing ratio of CGBM was highly correlated to the time-varying pattern of AE signals, indicating that the AE signals can closely reflect the internal particle-crushing situation of the CGBM.

(5) In this paper, a new method of monitoring the samples' AE signals during compression by an AE monitoring system was proposed to study the particle-crushing state. Further, the relationship between AE signals and particle crushing was established. This provides a feasible way to study particle-crushing characteristics during loading in the future.

Author Contributions: J.L. and Y.H. conceived and designed the experiments; M.L. and M.Q. performed the experiments; J.L. and Z.C. analyzed the data; J.L. wrote the paper; M.K. and Z.C. modified the paper.

Acknowledgments: Financial support for this work provided by the Fundamental Research Funds for the Central Universities (2015XKMS001) and the National Natural Science Foundation of China (No. 51774269) are gratefully acknowledged.

Conflicts of Interest: The authors declare no conflict of interest. 


\section{References}

1. Miao, X.X.; Zhang, J.X.; Guo, G.L. Waste Backfilling Method and Technology in Fully Mechanized Coal Mining; China University of Mining \& Technology Press: Xuzhou, China, 2010.

2. Miao, X.X. Progress of fully mechanized mining with solid backfilling technology. China Coal Soc. 2012, 37, 1247-1255.

3. Ju, F.; Huang, P.; Guo, S.; Xiao, M.; Lan, L.X. A roof model and its application in solid backfilling mining. Int. J. Min. Sci. Technol. 2017, 27, 139-143. [CrossRef]

4. Zhang, J.X.; Zhang, Q.; Spearing, A.J.S.; Miao, X.X.; Guo, S.; Sun, Q. Green coal mining technique integrating mining-dressing-gas draining-backfilling-mining. Int. J. Min. Sci. Technol. 2017, 27, 17-27. [CrossRef]

5. Huang, Y.L. Ground Control Theory and Application of Solid Dense Backfill in Coal Mines. Ph.D. Thesis, China University of Mining and Technology, Xuzhou, China, 2012.

6. Zhang, Q. Roof Control Mechanism by Coordination with Backfilled Body and Backfill Support in Solid Backfill Mining Technology. Ph.D. Thesis, China University of Mining and Technology, Xuzhou, China, 2015.

7. Chen, Q.F.; Niu, W.J.; Chen, Q.L.; Liu, J.G.; Fan, Q.Y. Improvement of Knothe model and analysis on dynamic evolution law of strata movement in fill mining. J. China Univ. Min. Technol. 2017, 2, 250-256.

8. Zhao, G.Y.; Wu, H.; Xu, Z.W.; Li, Z.Y.; Wang, E.J. Experimental study on load-bearing mechanism and compaction characteristics of mine filling materials. J. China Univ. Min. Technol. 2017, 6, 1251-1258, 1266.

9. Cao, Z.Z.; Du, F.; Li, Z.H.; Wang, Q.; Xu, P.; Lin, H. Research on instability mechanism and type of ore pillar based on the fold catastrophe theory. CMES-Comp. Model. Eng. Sci. 2017, 113, 275-293.

10. Li, M.; Zhang, J.X.; Zhou, N.; Zhang, Q. Deformation and failure analysis of river levee induced by coal mining and its influence factor. CMES-Comp. Model. Eng. Sci. 2017, 113, 183-194.

11. Lu, Y.Y.; Song, C.P.; Jia, Y.Z.; Lin, Q. Analysis and numerical simulation of hydrofracture crack propagation in coal-rock bed. CMES-Comp. Model. Eng. Sci. 2015, 105, 69-86.

12. Lei, X.L.; Masuda, K.; Nishizawa, O.; Jouniaux, L.; Liu, L.; Ma, W.; Satoh, T.; Kusunose, K. Detailed analysis of acoustic emission activity during catastrophic fracture of faults in rock. J. Struct. Geol. 2004, 26, 247-258. [CrossRef]

13. Miao, X.X.; Zhang, J.X.; Guo, G.L. Study on waste-filling method and technology in fully-mechanized coal mining. China Coal Soc. 2010, 35, 1-6.

14. Huang, Y.L.; Zhang, J.X.; Zhang, Q.; Nei, S.J.; An, B.F. Strata movement control due to bulk factor of backfilling body in fully mechanized backfilling mining face. Min. Saf. Eng. 2012, 29, 162-167.

15. Liu, Z. Compaction Properties of Gangue and Its Application in Backfilling Coal Mining. Ph.D. Thesis, China University of Mining and Technology, Xuzhou, China, 2014.

16. Yilmaz, E.; Kesimal, A.; Ercikdi, B. Evaluation of acid producing sulphidic mine tailings as a paste backfill. Turk. J. Earth Sci. 2004, 17, 11-19.

17. Yilmaz, E.; Belem, T.; Benzaazoua, M.; Kesimal, A.; Ercikdi, B. Evaluation of the strength properties of deslimed tailings paste backfill. Miner. Resour. Eng. 2007, 12, 129-144.

18. Yilmaz, E.; Fall, M. Paste Tailings Management, 1st ed.; Springer International Publishing AG: Basel, Switzerland, 2017.

19. Marsal, R.J. Mechanical Properties of Rockfill Embankment Dam Engineering; John Wiley Sons Inc.: New York, NY, USA, 1973; pp. 109-200.

20. Marsal, R.J. Large scale testing of rockfill materials. J. Soil Mech. Found. Div. 1967, 93, $27-43$.

21. Marsal, R.J. Earth-Rock Dam Engineering; China Water Press: Lianyungang, China, 1979.

22. Kong, D.Z.; Zhang, B.Y.; Sun, X. Triaxial tests on particle breakage strain of artificial rockfill materials. Chin. J. Geotech. Eng. 2009, 31, 464-469.

23. Hardin, C.S. Crushing of soil particles. J. Geotech. Eng. 1985, 111, 1177-1192. [CrossRef]

24. Kjaernsli, B.; Sande, A. Compressibility of some coarse-grained materials. In Proceedings of the 1st European Conference on Soil Mechanics and Foundation Engineering, Weisbaden, Germany, 15-18 October 1963; pp. 245-251.

25. Hall, E.B.; Gordon, B.B. Triaxial testing with large-scale high pressure equipment. In Laboratory Shear Testing of Soils; ASTM International: West Conshohocken, PA, USA, 1963; Volume 361, pp. 315-328.

26. Liu, H.L.; Qin, H.Y.; Gao, Y.F.; Zhou, Y.D. Experimental study on particle breakage of rockfill and coarse aggregates. Rock Soil Mech. 2005, 26, 562-566. 
27. Li, G.Y.; Fu, H.; Mi, Z.K. Test study on behaviors of grain crushing for rockfill materials. Rock Soil Mech. 2006, 27, 575-578.

28. Fu, H.; Lin, H.; Cai, Z.Y. Influencing factors for particle breakage of coarse grained soil. Nat. Sci. 2009, 37, $75-79$.

29. Cai, Z.Y.; Li, X.M.; Guan, Y.F.; Huang, Y.H. Particle breakage rules of rockfill materials. Chin. J. Geotech. Eng. 2016, 38, 923-929.

30. Gao, Y.F.; Zhang, B.; Liu, W.; Yan-Mei, A.I. Experimental study on particle breakage behavior of rockfills in large-scale triaxial tests. Rock Soil Mech. 2009, 30, 1237-1240.

31. Li, M.; Zhang, J.X.; Zhou, N.; Huang, Y. Effect of particle size on the energy evolution of crushed waste rock in coal mines. Rock Mech. Rock Eng. 2017, 50, 1347-1354. [CrossRef]

32. Zhang, J.X.; Li, M.; Liu, Z.; Zhou, N. Fractal characteristics of crushed particles of coal gangue under compaction. Powder Technol. 2017, 305, 12-18. [CrossRef]

33. Zhou, N.; Han, X.L.; Zhang, J.X.; Li, M. Compressive deformation and energy dissipation of crushed coal gangue. Powder Technol. 2016, 297, 220-228. [CrossRef]

34. Wang, G.P. Studies on the Recovery of Coal Gangues in Fuxin District Liaoning Province. Ph.D. Thesis, Chengdu University of Technology, Chengdu, China, 2005.

35. Fu, Z.A.; Feng, J.Y. Concrete Faced Rock Fill Dam; Huazhong University of Science and Technology Press: Wuhan, China, 1993.

36. Qin, S.Q.; Li, Z.D.; Zhang, Z.Y. An Introduction to Acoustic Emission Techniques in Rocks; Southwest Jiaotong University Press: Chengdu, China, 1993.

37. Nan, L.; Enyuan, W.; Enlai, Z.; Yankun, M.; Fule, X.; Weihua, Q. Experiment on acoustic emission of rock damage and fracture under cyclic loading and multi-stage loading. China Coal Soc. 2010, 35, 1099-1103.

(C) 2018 by the authors. Licensee MDPI, Basel, Switzerland. This article is an open access article distributed under the terms and conditions of the Creative Commons Attribution (CC BY) license (http:/ / creativecommons.org/licenses/by/4.0/). 